\title{
Memes e orações subordinadas adverbiais no 9 ano do Ensino Fundamental: uma abordagem estatística
}

\author{
Memes and subordinate clauses adverbs in the 9th elementary school year: a statistical \\ approach
}

Memorias y oraciones subordinadas adverbiales en el 9ํaño de la Enseñanza

Fundamental: un enfoque estadístico

\section{Brenda Maria Soares ${ }^{1 *}$, Adriana $\mathrm{Pin}^{2}$}

\begin{abstract}
RESUMO
Objetivos: Este artigo propõe apresentar estratégias com memes no ensino de orações subordinadas adverbais, em Língua Portuguesa, para facilitar o entendimento dos alunos e apresentar conclusões sobre a valência deste trabalho. Método: É composto de aulas com leitura e construção de memes. Resultados: A amostra é de 30 alunos do 9․ ano do Ensino Fundamental da Escola Estadual de Ensino Fundamental e Médio Jacaraípe, do município de Serra-ES. Cem por cento dos alunos não tinham debatido o assunto antes e também entenderam que memes eram compostos de figuras e frases. Cinquenta e três por cento dos alunos disseram ter facilidade de entender Orações Subordinadas Adverbiais e noventa por cento confirmaram entender melhor o assunto dessas orações quando se trabalha com memes. Noventa por cento dos alunos ficaram satisfeitos com as aulas e disseram terem aprendido bem o assunto. Conclusão: Foi possível perceber que o trabalho agradou muito aos alunos e que os mesmos realmente aprenderam o conteúdo, conforme afirmaram nas respostas no questionário aplicado e até sugeriram utilizar memes para o ensino de outros assuntos na Língua Portuguesa.
\end{abstract}

Palavras-chave: Memes; Estatísticas; Educação.

\begin{abstract}
Objectives: This article proposes to present strategies with memes in the teaching of subordinate clauses in Portuguese, to facilitate students' understanding and to present conclusions about the validity of this work. Method: It consists of classes with reading and building memes. Results: The sample is 30 students from the 9th grade. year of the Elementary School of the State School of Elementary and Middle School Jacaraípe, municipality of Serra-ES. One hundred percent of the students had not debated the subject before and also understood that memes were composed of figures and phrases. Fifty-three percent of the students said they were easy to understand Adverbial Subordinate Sentences and ninety percent confirmed that they better understand the subject of these sentences when working with memes. Ninety percent of the students were satisfied with the classes and said they learned the subject well. Conclusion: It was possible to perceive that the work was very pleasing to the students and that they really learned the content, as stated in the answers in the questionnaire applied and even suggested using memes to teach other subjects in the Portuguese Language.
\end{abstract}

Key-words: Memes, Statistics, Education.

\footnotetext{
${ }^{1}$ Mestre em Educação pela Fac. Vale do Cricaré, Professora da rede estadual/SEDU, Jacaraípe, Serra-ES.

2 Doutora em Letras-UFES, Professora do Inst. Federal do Espírito Santo (IFES) - Campus São Mateus-ES.

*E-mail: brendaprofessorinha@hotmail.com.
}

SUBMETIDO EM: 12/2017

ACEITO EM: 01/2018

PUBLICADO EM: 11/2018 


\section{RESUMEM}

Objetivos: En este artículo se propone presentar estrategias en la enseñanza de los memes adverabais cláusulas subordinadas, en portugués, para facilitar la comprensión de los estudiantes y presentar conclusiones acerca de la valencia de este trabajo. Método: Se compone de clases con lectura y construcción de memorias. Resultados: La muestra es de 30 alumnos del 9‥ año de la Enseñanza Fundamental de la Escuela Estatal de Enseñanza Fundamental y Medio Jacaraípe, del municipio de Serra-ES. Cien por ciento de los alumnos no habían debatido el asunto antes y también entendieron que memes estaban compuestos de figuras y frases. Cincuenta y tres por ciento de los alumnos dijeron tener facilidad de entender Oraciones Subordinadas Adverbios y noventa por ciento confirmaron entender mejor el asunto de esas oraciones cuando se trabaja con memes. El noventa por ciento de los alumnos se quedaron satisfechos con las clases y dijeron haber aprendido bien el asunto. Conclusión: Se ha podido ver que el trabajo muy satisfechos a los estudiantes y que realmente aprendieron contenido, como se indica en las respuestas del cuestionario e incluso sugirió el uso de los memes para la enseñanza de otras materias en portugués.

Palabras clave: Memos, Estadísticas; Educación.

\section{INTRODUÇÃO}

A estatística é uma ferramenta de que se dispõe para trabalhar a percepção de como dados importantes impactam em algum setor da vida, seja ele econômico, social, da educação, ou de qualquer empreendimento que visa algo de útil para a coletividade ou para alguns, até mesmo uma única pessoa.)A Estatística se interessa pelos métodos científicos para a coleta, a organização, o resumo, a apresentação e análise de dados, bem como na obtenção de conclusões válidas e na tomada de decisões razoáveis baseadas em tais análises MEDEIROS (2007.

Considerando a presença dos memes na mídia virtual, e sabendo que são apreciados por grande parte dos estudantes, considerou-se importante elaborar este artigo para demonstrar a utilidade da estatística, analisando os resultados obtidos nas aulas de Língua Portuguesa em uma turma de 30 alunos do 9‥ Ano do Ensino Fundamental em uma escola pública no estado do Espírito Santo. Para tornar mais evidente, Medeiros (2007) diz que, ao examinar um grupo qualquer, considerando todos os seus elementos, trata-se da população ou universo. Nem sempre isso é possível. Nesse caso, examina-se uma pequena parte chamada amostra. É o que acontece nessa pesquisa.

Dessa forma, coletaram-se os resultados de uma pesquisa nessa turma e relacionaram-se, estatisticamente, as respostas obtidas. A partir disso, aproveitou-se para esclarecer um tanto mais o que são os memes e como os mesmos vão ocupando espaços da internet. No item 1, abordamos, pois, sobre o contato dos alunos com os memes e no item 2 a pesquisa propriamente dita acerca dos memes, o que embasa a pesquisa. Horta (2015) explica que a concepção de meme de maneira simples e direta é o fenômeno que se configurou na web como algo (uma ideia ou uma informação) que se replica no tempo e no espaço.

Enquanto no item 1, estatisticamente trabalhou-se com várias tabelas; no item 2, foram usados gráficos ilustrativos para demonstrar a utilidade estatística nas análises de resultados na educação. Conforme o Nunes (2017) afirma que "temos de testar sistematicamente nossas hipóteses sobre a natureza da realidade, mesmo aquelas que parecem verdadeiras, lógicas ou evidentes." (informação verbal). Com essas considerações, passou-se a abordar os memes na internet.

O presente estudo tem como objetivo aproveitar os memes nas aulas de Língua Portuguesa, apresentando uma estatística sobre a qualidade do trabalho com esse recurso e demonstrar a aceitação dos estudantes com essa prática. Para Souza (2014) interessa considerar a relação linguagem, tecnologia e práticas sociais, tomando o fenômeno linguístico a partir de suas intenções sócio comunicativas, em que os interlocutores ocupam espaços de interação, histórico-social, percebendo o uso da linguagem como forma de agir socialmente, de interagir com os outros. Assim, aproveitar os memes em aulas de Língua Portuguesa pode e deve gerar um grande interesse por parte dos aprendizes. 
O método de trabalho foi constituído de aulas com memes envolvendo o conteúdo de análise sintática, especificamente as orações subordinadas adverbiais. Foi realizada uma pesquisa aplicando questionários para os alunos, os quais responderam sobre como se sentiram em relação ao uso dos memes, qual a aprendizagem que tiveram e sobre a validade, para eles, deste método. Para demonstrar estatisticamente, os resultados, valeu-se de tabelas e gráficos. Consoante Gerhard \& Silveira (2009), só se inicia uma pesquisa se existir uma pergunta, uma dúvida para a qual se quer buscar a resposta. Pesquisar, portanto, é buscar ou procurar resposta para alguma coisa.

O objetivo deste estudo é observar se os memes podem ser um importante recurso visual-textual para o ensino da Língua Portuguesa, notadamente no conteúdo da sintaxe, envolvendo as orações subordinadas, com destaque para as adverbiais. Também se pretende verificar o aproveitamento que os alunos tiveram com as atividades e saber da satisfação deles em relação ao tipo de trabalho desenvolvido. Objetiva-se, ainda, descobrir informações bibliográficas já existentes a respeito de memes e sua aplicação em trabalhos docentes, deixando aberto o debate para futuros trabalhos de pesquisa.

\section{METODOLOGIA}

A utilização de um questionário para 30 alunos do 9․ ano do Ensino Fundamental da Escola Estadual de Ensino Fundamental e Médio de Jacaraípe-ES.

O levantamento de dados ocorreu pela aplicação de um questionário de 10 perguntas aos alunos, com nove das mesmas tendo respostas de múltipla escolha. A análise dos resultados foi feita através da leitura das respostas, verificando a percentagem de cada tipo de resposta.

Este questionário trouxe questões acerca do uso de memes no ensino de Língua Portuguesa, sendo que as mesmas se referem ao conhecimento prévio deles sobre o assunto, às percepções durante as aulas e aos resultados que julgam terem sido obtidos. Houve perguntas, como, "Você, alguma vez na sua vida escolar anterior chegou a estudar algo sobre memes?", "Onde ocorrem os memes?" e "Você se interessa em estudar conteúdos gramaticais com a observação dos memes durante a aula?", entre outras, num total de 10 perguntas e respostas de múltipla escolha ou pessoais na última delas.

Cada responsável pelos alunos assinaram o TCLE (Termo de Consentimento Livre e Esclarecido), tendo ciência de que o aluno estava livre para participar do questionário e que suas identidades seriam mantidas em sigilo no tocante às respostas dadas. Essa orientação também foi transmitida aos alunos, em sala de aula. Este estudo foi aprovado pelo Comitê de Ética em Pesquisa do Instituto do Vale do Cricaré-ES sub número CAAE: 98140818.5 .0000 .8207$.

\section{RESULTADOS E DISCUSSÃO}

\section{Dados estatísticos sobre o questionário acerca de memes}

Com a aplicação do questionário, foi possível obter as informações desejadas para a pesquisa, sendo que todos os trinta alunos responderam a todas as questões que constam na tabela 1.

Acerca da primeira questão, foi possível perceber que nenhum aluno teve a oportunidade de estudar com e sobre memes anteriormente. Todos os trinta alunos entenderam que memes são compostos por figura e frase - logicamente frases curtas, como se depreende das respostas à segunda questão.

As respostas dadas à terceira pergunta mostram que $53 \%$ dos entrevistados - alunos do 9 . ano disseram não ter dificuldades em entender orações subordinadas, enquanto $47 \%$ dos alunos dizem não ter essa facilidade.

Ao analisar as respostas da quarta questão da tabela 1, percebe-se a afirmação de que $90 \%$ dos alunos sentiram mais facilidade para entender o assunto orações subordinadas adverbiais e apenas 10\% responderam que não ajudou. 
Tabela 1. Tipos de respostas dos alunos, $n=30$.

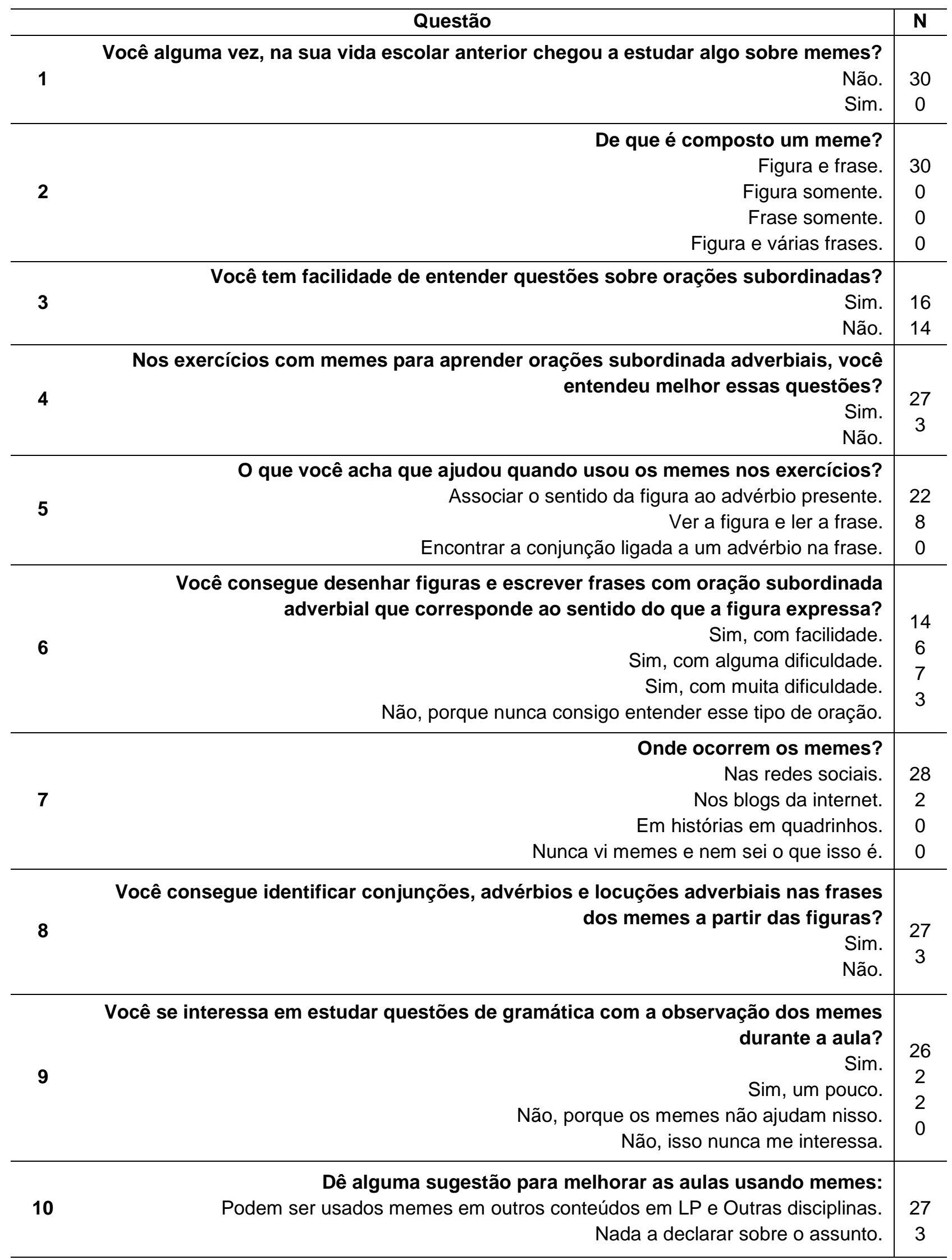

Fonte: Pesquisa direta, 2018. 
Na questão de número cinco, havia a proposta de três respostas possíveis, porém somente duas foram marcadas. Setenta e três por cento responderam que é "Associar o sentido da figura ao advérbio presente" e $27 \%$ disseram que aprenderam melhor com "Ver a figura e ler a frase". Nenhum se preocupou em encontrar a conjunção ligada a um advérbio na frase.

A sexta pergunta tinha 4 respostas possíveis, sendo que $46 \%$ disseram ter facilidade de desenhar figuras e escrever frases com oração subordinada adverbial; $20 \%$ têm alguma dificuldade; $23 \%$ encontram muita dificuldade; e 10\% dizem que encontram muita dificuldade porque nunca conseguem entender $\mathrm{o}$ assunto.

Observando as respostas dadas à pergunta número sete, vê-se que $93 \%$ dos entrevistados dizem encontrar os memes nas redes sociais e 17\%, em blogs na internet, já as outras duas respostas não tiveram marcação.

Vê-se que na questão de número oito, $90 \%$ dos alunos conseguem identificar conjunções, advérbios e locuções adverbiais em frases, pelas figuras nos memes, e 10\% afirmam que não.

Na resposta da questão nove, $87 \%$ dizem se interessar em estudar gramática com ajuda dos memes; quase $7 \%$ dizem ter alguma dificuldade e outros quase $7 \%$ afirmam que memes têm nada a ver com isso.

Finalmente, na questão dez, $90 \%$ dos alunos sugerem que se use memes também no ensino de outros conteúdos da Língua Portuguesa e 10\% tinham nada a declarar a respeito.

Diz-nos IGNÁCIO (2010) que a utilidade da estatística se expressa no seu uso, uma vez que grande parte das hipóteses científicas, independentemente da área, precisa passar por um estudo estatístico para ser aceita ou rejeitada. Por isso, nota-se que a estatística precisa estar presente em todos os campos que são objetos de pesquisas. Percebe-se que, no objeto verificado, conhecimento e opiniões de estudantes do 9‥ ano do Ensino Fundamental acerca de memes, algumas das 10 respostas receberam o mesmo número para Sim e para Não. Como se tratou de uma pesquisa mais sucinta, os motivos para isso ocorrer podem ser inferidos por comportamentos de tais alunos em relação ao interesse que demonstraram pelo assunto. A coincidência, evidenciada pelos dados acima, ocorre com as questões 4, 7, 8 e 10. Os três alunos que davam a resposta negativa eram sempre os mesmos.

O que os gráficos também evidenciam é que sempre a maior parte, maioria absoluta, gostou e aproveitou a utilização dos memes nas aulas para ensinar orações subordinada adjetivas adverbiais.

Para a autora-mestranda, este trabalho de pesquisa e a elaboração de tabelas e gráficos estatísticos demonstrou que é necessário praticar bastante elaboração de gráficos e outros elementos demonstrativos sobre pesquisas, uma vez que, a partir dessa prática, chega-se a ter mais recursos para evidenciar dados levantados.

Analisando os dados da pesquisa, percebe-se que há certos paradoxos no resultado. Por exemplo, na questão três, pouco mais da metade dos alunos afirma ter facilidade de entender o assunto orações subordinadas, o que, conforme se ouve de colegas que trabalham na disciplina de Língua Portuguesa, não é normal, pois nós mesmos verificamos isso em turmas anteriores. Outro ponto é que há alunos que são sempre destoantes em relação aos demais, pois nas questões 3, 6, 8 e 10 sempre os três mesmos alunos destoaram das respostas da maioria.

Deduz-se que a pesquisa demonstra que um questionário nunca é capaz de ser $100 \%$ confiável para afirmar a validade total do resultado, mas, por outro lado, é possível depreender que o assunto analisado tem pontos importantes a considerar, ou seja, introduzir um novo tipo de texto para trabalhar determinado assunto no ensino de línguas sempre tem seus benefícios: um, porque a novidade chama muito a atenção; e o outro, porque a mesmice desestimula os alunos. Sabe-se que o ensino e a aprendizagem da sintaxe no português é tarefa que inúmeros alunos detestam, e grande parte dos professores se sente com dificuldades para abordar com tranquilidade e segurança.

Nota-se, em algumas questões que um número muito grande, $90 \%$ dos alunos dizem ter tido grande aproveitamento no ensino. Mesmo que isso pareça um tanto exagerado, evidencia, no entanto, que o trabalho desenvolvido teve grande valor e que o tipo textual "memes" pode, sim, ter mais aplicação no ensino da Língua Portuguesa. 


\section{CONCLUSÃO}

A utilização de memes em aulas de Língua Portuguesa e a prática estatística para análise dos resultados dessa iniciativa foram os principais pontos destacados no presente artigo.

Memes estão presentes na internet, principalmente em blogs e páginas de redes sociais e significam, basicamente, imitação por meio de imagens e expressões - frases - com ironia, sarcasmo, humor simples, crítica mais ou menos forte, situações que chamam a atenção pelo inusitado. A popularização dos memes ocorre muito entre as pessoas mais jovens que compartilham, twittam e retwittam certas situações.

\section{REFERÊNCIAS}

1. ARAÚJO, Juliana Xavier de. Memes: a linguagem da diversão na internet, análise dos aspectos simbólicos e sociais dos rage comics. Rio de Janeiro: UNIVERSIDADE FEDERAL DO RIO DE JANEIRO, ESCOLA DE COMUNICAÇÃO, CENTRO DE FILOSOFIA E CIÊNCIAS HUMANAS, JORNALISMO, 2012.

2. BLACKMORE, Susan. Memes and 2008.2 Disponível em: <http://www.ted.com/talks/susan_blackmore_on_memes_and_temes>. Acesso em: 14 jan. 2014.

3. GERHARDT Tatiana Engel \& Silveira Denise Tolfo. Métodos de pesquisa. Porto Alegre: Editora da UFRGS, 2009.

4. GROSSMANN, Luís Osvaldo. Escolas têm computador, mas internet é desafio. Disponível em <http://www.convergenciadigital.com.br/cgi/cgilua.exe/sys/start.htm?UserActiveTemplate=site\&infoid=45873\&sid=14> Acesso em 8/11/2017.

5. HORTA, Natália Botelho. O meme como linguagem da internet: uma perspectiva semiótica. Brasília: Universidade de Brasília, 2015.

6. IGNÁCIO, Sérgio Aparecido. Importância da estatística para o processo de conhecimento e tomada de decisão. Curitiba: Nota Técnica Ipardes, № 6, outubro/2010.

7. LOPES, Marina. Sucesso nas redes sociais, memes também podem ensinar. Disponível em < http://porvir.org/sucesso-nas-redessociais-memes-tambem-podem-ensinar/> Acesso em 0711/2017.

8. MEDEIROS, Carlos Augusto de. Estatística aplicada à educação. Brasília: Universidade de Brasília, 2007.

9. Informação fornecida por NUNES durante a aula sobre Estatística, São Mateus-ES, 2018.

10. PASSOS, Marcos Vinícius Ferreira. O gênero "meme" em propostas de produção de textos: implicações discursivas e multimodais. Anais do SIELP. Volume 2, Número 1. Uberlândia: EDUFU, 2012.

11. RIBEIRO, Rogério Alves. Utilização da tecnologia da informação na educação pública em Santa Catarina. Caçador, SC: UNIARP, 2014.

12. SATYRO, Natália; SOARES, Sergei. A infraestrutura das escolas brasileiras de ensino fundamental:

13. SOUZA, C. F. Memes em aulas de português no ensino médio: linguagem, produção e replicação na cibercultura. Revista Philologus, Ano 20, No 60 Supl. 1: Anais da IX JNLFLP. Rio de Janeiro: CIFEFiL, set./dez.2014

14. um estudo com base nos censos escolares de 1997 a 2005. Brasília: IPEA, 2007.

15. Significado de Meme. Disponível em < https://www.significados.com.br/meme/ > Acesso em 8/11/2017 